- Relatively few people used NHS Direct when seeking to obtain NHS dental care.

- A local telephone helpline was used to direct people wanting NHS dental care to available services.

- Although some dental services are listed as taking NHS patients, long waiting lists can exist which mean those wanting care may not have the access to care they desire.

\title{
Access to NHS dentistry in South Cheshire: a follow up of people using telephone helplines to obtain NHS dental care
}

\author{
R. Harris ${ }^{1}$
}

Objective To follow up calls made to NHS Direct and South Cheshire Dental Helpline concerning getting access to an NHS dentist in South Cheshire.

Design Contact details of callers who had consented to a follow up call were passed by helpline staff to a researcher at regular intervals. In a structured interview, callers were asked why they had telephoned the helpline and whether they had subsequently obtained NHS dental care. Follow up calls continued until a total of 200 replies had been gathered, either by telephone or post (for those where telephone contact could not be made). Follow up calls were made between September 2001 and March 2002.

Results During the study period only three callers from South Cheshire contacted NHS Direct with a dental access query and consented to a follow up call, compared with 219 callers to South Cheshire Dental Helpline. Only 10\% were not contacted either by telephone or post. A comparison with figures for calls made to South Cheshire Dental Helpline between April 2000 and March 2001 suggests that during the study period a year later the access problem has improved. However, there were still a few areas in South Cheshire where significant numbers of dental access queries were being received. Twenty five per cent of unregistered and 22\% of registered callers still felt that they had problems getting access to NHS dental care after using information from the helplines.

Conclusion A small but significant number of people in South Cheshire have problems accessing NHS dental care.

In a speech to the Labour Party conference in September 1999, the Prime Minister Tony Blair made a pledge that by September 2001 'everyone in the country will be able once again to see an NHS dentist just by telephoning NHS Direct'. This was made against a background of a shift amongst general dental practitioners (GDPs) away from NHS treatment and towards independently funded

${ }^{1}$ Senior Lecturer in Primary Dental Care, 5th Floor, The University of Liverpool, School of Dentistry, Pembroke Place, Liverpool L3 5PS

Email:harrisrv@liverpool.ac.uk

\section{Refereed paper}

Received 12.08.02; Accepted 27.03.03

doi:10.1038/sj.bdj.4810601

๑ British Dental Journal 2003; 195: 457-461 dentistry, resulting in a reduced availability of NHS primary dental care particularly in some parts of the United Kingdom. This steadily increasing problem of getting access to NHS care was of concern to the profession, ${ }^{1}$ the public, and also to politicians. In a review of the number of written House of Commons questions, equitable access to NHS dentistry for all individuals was found to be the main concern of politicians in the field of oral healthcare, above concerns about the quality of services. ${ }^{2}$ The media also featured problems with access to NHS dentistry highly with a third of articles on dentistry published in 1994/5 broadsheet newspapers being concerned with access. ${ }^{2}$

The government did acknowledge that an access problem existed and took several initiatives to make NHS dentistry a "truly national service again: ${ }^{3}$ This included the setting up of around 50 dental access centres by March 2001, where patients who were not registered with a dentist could get a full range of NHS care. The Government now seem proud of their 'dental achievements'. Lord Hunt, speaking for the Government in May 2002 in response to a parliamentary question on NHS dentistry said, 'We have put in place a system whereby patients who have difficulty finding an NHS dentist can ring NHS Direct, who will refer them to the nearest NHS dentist. In many parts of the country that is having a very beneficial impact."

Regional differences in the availability of NHS dentistry have been reported, with GDPs in the South-East, South-West and London treating the highest proportions of private patients. ${ }^{5}$ GDPs in the North-West of England on the other hand appear to be predominantly NHS providers with one of the lowest proportion of private patients treated per practitioner. ${ }^{5}$ However, not all parts of the North-West are as fortunate. Cheshire, a county covering a large geographical area from the border with North Wales, around the perimeter to the South of Manchester, to the borders with Shropshire and Staffordshire is one such area where access to NHS dentistry has been a problem. In response, South Cheshire Health Authority set up a dental help-line to take queries from members of the public and this was advertised in a range of places including local newspapers and doctor's surgeries. Between April 2000 and March 2001 the helpline received an average of 100 calls per month from people seeking registration and/or treatment with an NHS dentist. People contacting the helpline would be informed of the nearest NHS dentist with whom they should be able to receive 


\section{RESEARCH}

care. A dental access centre set up in March 2001 in Macclesfield, one of the main towns in the area, was one of the potential options which could be given.

People wanting information on access to NHS dentistry could also have telephoned NHS Direct, the nurse-led 24-hour telephone helpline which has been set up as a major new way of increasing access to NHS services, particularly out-of-hours. ${ }^{6}$ The Government has declared that NHS Direct is to have a key role in rebuilding access to NHS dentistry. ${ }^{7}$ There is however little information available on how this has worked in practice now the service of NHS Direct has been extended nationwide.

This study reports the experience of people living in South Cheshire who contacted NHS Direct or South Cheshire Dental Helpline in an effort to find an NHS dentist. Given the information made available to them from these telephone helplines, were these people able to get the NHS care they wanted? Since the study is not a nationwide survey of access to NHS dentistry, the aim of the study was not to answer the research question of whether Tony Blair has managed to keep his pledge regarding access to NHS dentistry for the country as a whole, but to measure the extent to which, in the South Cheshire area, people once given access to the assistance of a telephone helpline, were able to obtain the NHS dental care they wanted.

\section{METHOD}

Ethical approval was gained for the study in August 2001. Staff operating call lines at South Cheshire Dental Helpline and NHS Direct (North-West) began asking all callers who telephoned with a dental access query from August 2001 onwards, if they would consent to their name, address, postcode and telephone number being passed on to a university researcher who would call them at a later date to ask how they got on trying to find an NHS dentist. Details of consenting callers were then passed on to the researcher at regular intervals, who made follow up calls from 2 weeks after the initial contact with the Helpline. NHS Direct used a postcode database for the South Cheshire area to determine which callers should be included in the study.

The telephone interview was carried out using a structured questionnaire using closed questions, although if the respondent wanted to elaborate further on their experience, this was written down. Several attempts were made to contact the individual by telephone, and where this was unsuccessful the interview schedule was posted enclosing a stamped, addressed envelope for a reply. A total of three possible mailings were done to try to follow up nonrespondents. Follow up calls were made between September 2001 and March 2002. The follow up calls were finished when a total of 200 replies had been gathered either by telephone or post.

\section{RESULTS}

The details of only three callers to NHS Direct and 219 callers to South Cheshire Dental Helpline were passed to researchers between August 2001 and March 2002. Of these, 192 were contacted by telephone and nine by post. Out of the $21(10 \%)$ who were not contacted, 4 (19\%) were known to have moved on or contact details were incorrect and no further means of contact were available. One person refused to be interviewed when they were contacted.

Table 1 shows the total number of calls made to South Cheshire Dental Helpline concerning dental access issues during the period of the study, grouped by the main localities in the area, and the number of callers in this period who had consented to follow up and those who were included in the study. It appears that about 13\% of callers contacting South Cheshire Dental Helpline refused the opportunity to be involved in the study. Table 1 also shows the figures available from the Health Authority for the total number of calls made to South Cheshire Dental Helpline between April 2000

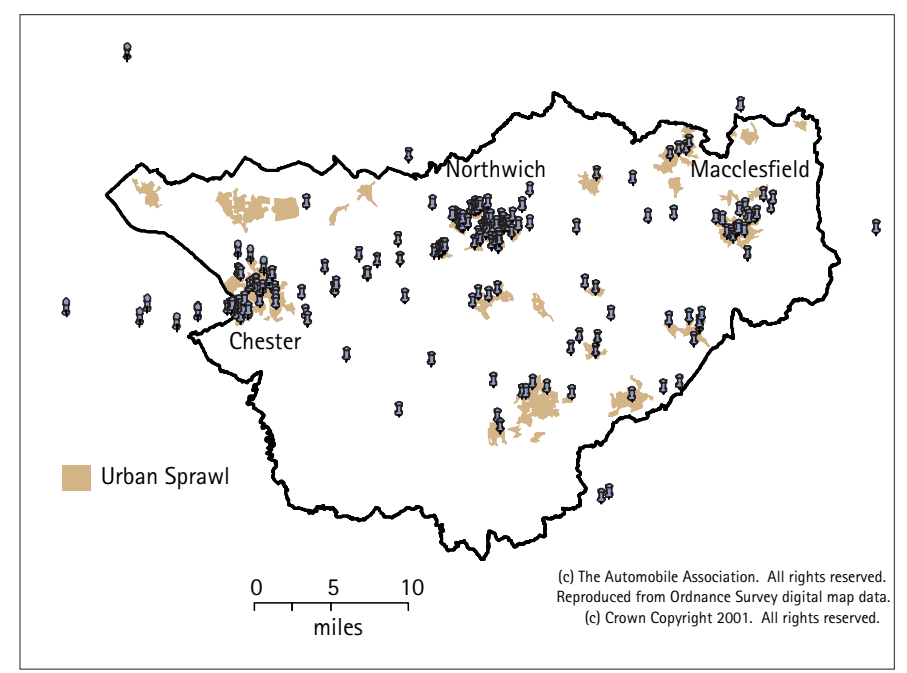

Fig. 1 Geographical distribution of 200 callers followed up in relation to South Cheshire boundary, based on callers' postcode

and March 2001. It appears likely that fewer calls were made between August 2001 and March 2002 than between in the same period a year previously, and this suggests that the access problem did improve in this time. In 2000/2001 there appears to have been a fairly even spread of queries throughout South Cheshire, whereas in 2001/2002 there appear still to be significant problems in the Chester and Northwich areas with other areas much less badly affected.

Figure 1 shows geographical distribution of the 200 callers interviewed. Twelve had postcodes outside South Cheshire boundaries, although most of these were near to the boundary. About a third were from rural areas $(32 \%, 64)$, a third from suburban areas (near to, but not actually living in the main towns, 36\%, (72)) and a third lived in a main town in the area $(32 \%, 64)$. Thirty nine per cent (78) of respondents were male and 61\% (122) were female. When the 200 callers were questioned, it transpired that this represented an enquiry about access to NHS dentistry for 246 people, $(180,73 \%)$, of these were aged between 25 and 64-years-old, $26(11 \%)$ were aged $18-24$ years, $13(5 \%)$ were aged 65 years or more and $27(11 \%)$ were under 18 years of age. This was because one caller might be making the enquiry about obtaining NHS dental care for both themselves and their husband or wife, or for their children. Subsequent questioning however was focused on the issues relevant only to the individual making the call to the helpline.

Of the 200 callers to NHS Direct and South Cheshire Dental Helpline who were interviewed, 59 (30\%) made the enquiry because they had toothache, $5(3 \%)$ because they had some dental trauma, 29 (15\%) because they felt they needed some treatment such as a filling, but were not in pain at present, and the remaining 107 (54\%) because they wanted to register with a dentist for routine care. Seventy seven per cent (153) of responders to the study reported that they were not registered with a dentist in the area at the time of calling. This comprised 74 people who had just moved into the area with the remainder being either those whose registration with a dentist had lapsed and they found they could not re-register, or those who had not been to a dentist for many years.

Twenty one of the remaining 47 responders reported having seen a dentist in the area within the previous 15 months, but either had been told that their dentist would be retiring (10 people) or that the dentist would no longer be treating patients on an NHS basis (11 people). Twenty six people reported that they were actually still currently registered with a dentist. The reason given for telephoning the helpline was either that they wanted to change dentists (18, 


\begin{tabular}{|c|c|c|c|c|}
\hline Locality & $\begin{array}{l}\text { Number of calls } \\
\text { to South } \\
\text { Cheshire Dental } \\
\text { Helpline } \\
\text { April 2000- } \\
\text { Mar2001 }\end{array}$ & $\begin{array}{l}\text { Number of calls } \\
\text { to South } \\
\text { Cheshire Dental } \\
\text { Helpline } \\
\text { Aug 2001- } \\
\text { Mar2002 }\end{array}$ & $\begin{array}{l}\text { Number of } \\
\text { callers } \\
\text { consenting to } \\
\text { follow up call } \\
\text { Aug 2001- } \\
\text { Mar2002 }\end{array}$ & $\begin{array}{l}\text { Number of } \\
\text { callers } \\
\text { contacted with } \\
\text { follow up call } \\
\text { Aug 2001- } \\
\text { Mar2002 }\end{array}$ \\
\hline Chester & 200 & 88 & 66 & 58 \\
\hline Crewe & 200 & 13 & 9 & 7 \\
\hline Nantwich & 160 & 7 & 4 & 4 \\
\hline Northwich & 240 & 69 & 66 & 63 \\
\hline Winsford & 160 & 18 & 5 & 5 \\
\hline Macclesfield & 200 & 35 & 26 & 24 \\
\hline Congleton & 175 & 11 & 6 & 6 \\
\hline Other & 100 & 42 & $40^{+}$ & $34^{*}$ \\
\hline Total & 1,435 & 283 & 222 & 201 \\
\hline
\end{tabular}

$69 \%$ ), or because their dentist was unable to undertake either the emergency treatment (six people) or routine treatment (two people) they required.

It is interesting to note that of the 47 people who had reported having seen a dentist in the area within the previous 15 months, $38(81 \%)$ had gone on to contact the surgeries suggested by the helplines, with five of the nine deciding to remain with their original practitioner. The others did nothing about it because they did not like the alternatives suggested by the helpline, either because the surgeries suggested were too far away, or they felt that the surgery suggested had a bad reputation. All but $6(16 \%)$ of those who tried to obtain an appointment with one of the surgeries suggested were successful. In all, $10(22 \%)$ of the original 47 responders who reported being registered or having seen a dentist in the area within the previous 15 months reported feeling that they still had a problem accessing NHS dental care in the area after they had an opportunity to use the information given by the helplines (presumably this includes those who had been given suggestions of alternative dentists by the helplines, but the callers had not found the alternatives suggested acceptable). The proportion reporting having problems accessing NHS care after having been given information from the helpline was very similar for those who reported not being registered with a dentist $(25 \%, 38)$.

Of the 200 responders, 171 (86\%) went on, using the information given to by the helplines, to try to find an NHS dentist, and of these 131 (77\%) managed to make arrangements to see an NHS dentist (Table 2). Almost a quarter $(23 \%, 40)$ of those who had pursued the matter did not obtain the NHS dental care they wanted despite the information given to them. When all 200 responders were asked whether they felt that they still had problems getting access to NHS care, a similar percentage $(24 \%, 48)$ said that they did. When the 40 people who had tried using the helpline information and who had still not been successful in obtaining NHS care were asked why they had not been able to make an appointment at one of the suggested surgeries, four people said that the dentist would not see them as an NHS patient, 18 said that the waiting list for treatment was too long, and 15 said they could not get on the NHS patient list at the surgery. Of the 40 who were unable to find NHS care, 16 were wanting care because they had toothache (Table 2).

Many of the callers elaborated on their experience with similar stories reported. 'I moved into the area and signed on with a doctor straight away. I went along to three fairly local dentists only to be told that they couldn't take any more NHS patients and I was to come back in 2-3 months time. One dentist I went to in September, I called back in December and again in February. No, books were full. I phoned the helpline and they gave me two names, but when I tried these it was the same story. I thought what the heck am I meant to do?' 'There was a two year waiting list for the dentist suggested by the helpline.' 'I approached them in the Autumn and was told they had a waiting list. Its now March and I've still not got an appointment.'

\begin{tabular}{|c|c|c|c|}
\hline \multirow[b]{2}{*}{$\begin{array}{l}\text { Immediate reason for } \\
\text { contacting the Helpline }\end{array}$} & \multicolumn{2}{|c|}{$\begin{array}{l}\text { Do you feel you still have problems } \\
\text { getting access to NHS dental care? }\end{array}$} & \multirow[b]{2}{*}{$\begin{array}{l}\text { Total number of } \\
\text { callers interviewed }\end{array}$} \\
\hline & $\begin{array}{c}\text { No.(\%) callers } \\
\text { interviewed } \\
\text { No }\end{array}$ & $\begin{array}{c}\text { No. }(\%) \text { callers } \\
\text { interviewed } \\
\text { Yes }\end{array}$ & \\
\hline I wanted a check up & $75(84 \%)$ & $14(16 \%)$ & 89 \\
\hline $\begin{array}{l}\text { I felt I had a non-urgent need } \\
\text { for treatment }\end{array}$ & $20(74 \%)$ & $7(26 \%)$ & 27 \\
\hline I had toothache & $34(68 \%)$ & $16(32 \%)$ & 50 \\
\hline I had injured my tooth or mouth & $2(40 \%)$ & $3(60 \%)$ & 5 \\
\hline Total & $131(77 \%)$ & $40(23 \%)$ & 171 \\
\hline
\end{tabular}




\begin{tabular}{|c|c|c|c|c|c|}
\hline \multirow{2}{*}{$\begin{array}{l}\text { Type of area } \\
\text { where caller } \\
\text { lived }\end{array}$} & \multicolumn{4}{|c|}{$\begin{array}{l}\text { Distance travelled between home and dental practice for } \\
\text { callers who had managed to obtain NHS dental care }\end{array}$} & \multirow{2}{*}{$\begin{array}{l}\text { Total } \\
\text { Number of } \\
\text { callers } \\
\text { interviewed } \\
\text { who obtained } \\
\text { NHS care }\end{array}$} \\
\hline & $\begin{array}{l}\text { No. callers } \\
\text { interviewed } \\
\text { travelling }<2 \\
\text { miles }\end{array}$ & $\begin{array}{c}\text { No. callers } \\
\text { interviewed } \\
\text { travelling 2-9 } \\
\text { miles }\end{array}$ & $\begin{array}{l}\text { No. callers } \\
\text { interviewed } \\
\text { travelling } 10-20 \\
\text { miles }\end{array}$ & $\begin{array}{l}\text { No. callers } \\
\text { interviewed } \\
\text { travelling > } \\
20 \text { miles }\end{array}$ & \\
\hline Rural & 8 & 31 & 2 & 1 & 42 \\
\hline Suburban & 27 & 21 & 1 & 0 & 49 \\
\hline Urban & 21 & 17 & 2 & 0 & 40 \\
\hline Total & 56 & 69 & 5 & 1 & 131 \\
\hline
\end{tabular}

Eleven of those who had tried unsuccessfully to get NHS care reported that they had since resorted to becoming a private patient 'I contacted the two dentists suggested by the helpline. One was the Dental Access Centre but they would only see me in six weeks time. I then tried a couple of dentists with which people at work were registered but I couldn't get in, so I had to go private.' 'They couldn't see me as an NHS patient until November (six weeks), but would see me in one week if I paid privately.' 'There was a long wait for treatment at the dental practices they suggested so I decided to pay privately with my old dental practice.'

Twenty nine out of the 200 responders did not pursue the matter further once they had obtained information from the helplines. When questioned, this was for a variety of reasons such as: the practices suggested were too far away (four people), the immediate problem went away (four people), not having got around to it yet (five people), problem sorted out privately at another surgery (eight people), and having decided to stay with their original dentist (five people). South Cheshire Health Authority set a dental access target for 2001/2 that residents who wish to avail themselves of an NHS dental service should be able to do so within a nine mile radius of their home. The distance target was met for the majority $(125,95 \%)$ of those who had managed to obtain NHS dental care, even for most of those living in rural areas (Table 3). However, this distance target was perceived by some as being an unacceptable distance to travel to the dentist. 'I had a hole in my tooth. I'd tried about 10 dentists in the area before I telephoned the helpline. In the end I had to travel to Hoole, but I can't drive so I have to get two buses, one into Chester and one from Chester to Hoole. It's difficult as I have three children, a baby and two aged 3 and 4.' (she lived in a suburban area, between 2 and 9 miles from the dental practice). 'Its not what you call a local dentist. Even the ones on the list from the helpline were just taking names and putting you on a waiting list and it would be next year before I was seen.' 'I'm going to change when I can get a dentist nearer home. I need some work doing so I'll get it done and then I'll change. Its not as near as I'd like but I've tried the dentists in Northwich and found that I'd have to wait several months before they could see me. They said they would put me on a waiting list' (lived 2-9 miles from the practice in an urban area).

South Cheshire Health Authority also set a dental access target for 2001/2 that residents who wish to avail themselves of an NHS dental service should be able to avail themselves of a service within four weeks. They were less successful in meeting this target since of the 131 people who had managed to obtain NHS care, 29 (22\%) had an appointment that was more than four weeks away. Out of the 34 people who had contacted the helpline because they had toothache and who had managed to get NHS dental care, 14 (41\%) were seen within 24 hours, 12 (35\%) were seen within 1-2 days, five (15\%) were seen within a week and three (9\%) had an appointment for more than four weeks away.

Most people had called the helplines after trying to find an NHS dentist themselves. Sixty one per cent (122) had obtained the telephone number from a dental practice where they had tried unsuc- cessfully to obtain NHS care. Thirteen per cent (25) had obtained the telephone number from the Yellow Pages, 8\% (16) from a doctor's surgery, 5\% (10) from the Health Authority, 5\% (10) from a friend or relative, 3\% (5) from the internet, with the remainder obtaining the number from either newspaper advertisements, maternity information packs, or the County Council welcome pack. Out of the 200 callers interviewed. 154 had tried other dental practices before telephoning the helplines. The number of practices contacted varied from between one and 20 dental practices. Eleven people had contacted between 10 and 20 practices unsuccessfully. Of those contacting dental practices prior to using the helplines, the mean number of practices contacted was 3.6 (standard deviation 3.36).

\section{DISCUSSION}

Although a high proportion of callers who consented to be interviewed were contacted $(90.5 \%, 201)$, there were a further 64 people who had contacted the South Cheshire Dental Helpline for advice about obtaining NHS dental care, but who were unwilling to take part in the study. Unfortunately it was not possible to obtain figures for the numbers of people who made calls to NHS Direct during the study period, but who did not want to be followed up, but if the proportion of refusals was about the same as for the South Cheshire Dental Helpline, at most, one other person contacted NHS Direct with this type of query within the study period and refused to take part in the study. The true response rate of the study therefore, taking into account refusals was in the region of 70.0\% (200).

The Government's claim that NHS Direct is playing a key role in directing those searching for NHS dental care is not substantiated by the findings in this study. Very few people indeed from South Cheshire had contacted NHS Direct (North West) with an enquiry about getting access to an NHS dentist during the study period, even though NHS Direct (North West) was able to do this from April 2001. The South Cheshire Dental Helpline seems to be more heavily used for this purpose, and it may be that the existence of an alternative telephone helpline, meant that calls that might have been made to NHS Direct were made instead to the local alternative. Also, the availability of the details of the South Cheshire Dental Helpline may be greater than for those of NHS Direct, particularly since the majority of callers to the South Cheshire Dental Helpline were directed there by a dental practice at which they had tried, unsuccessfully, to obtain care. The experience in South Cheshire does seem to confirm the evidence of first wave NHS Direct pilot sites, that NHS Direct's impact on dental services were not immediate, call volumes were relatively low, although increasing, and that there was a perception that this was mainly an out-of-hours service. ${ }^{6}$

This study is based on a group of people who already appear to have sufficient difficulty in accessing NHS dentistry to have necessitated them contacting either NHS Direct or the South Cheshire Dental Helpline. About three-quarters of those studied had already tried contacting an average of between three and four 
dental practices before telephoning for advice. Although the sample cannot be seen as representative of the wider population, it is interesting that $24 \%$ of callers, even after receiving information from the helplines still felt that they had problems accessing NHS dental care. Assuming that the South Cheshire Dental Helpline has been used as a substitute for NHS Direct in this area, Tony Blair's vision of the role of a telephone helpline such as NHS Direct in directing those who want dental care towards where the service is available locally, does seem to be flawed by the fact that some of the services included on lists as being able to take NHS patients, may be in reality putting patients on waiting lists or turning them away altogether. Anderson, anticipating the role of the fully established NHS Direct in handling calls about access to NHS dental care saw that the new service might actually merely serve to highlight the non-existent availability of NHS services in some areas and 'for many unregistered patients it may become not so much a pathway to care as a dead end: ${ }^{6}$

On the other hand, access to NHS dentistry in South Cheshire does seem to have improved, with the numbers of those making telephone enquiries about access to NHS dental care diminishing significantly. Macclesfield Dental Access Centre opened in March 2001, and this probably accounts for some of the reduction in calls to the helpline. Expansion of existing General Dental Services through the Dental Care Development Fund and Investing in Dentistry also occurred in 2001 and this may also have eased the access problem. Chester is about 40 miles from the access centre in Macclesfield and Northwich is about 20 miles. A satellite service in Northwich, Winsford and Tarporley (a small town outside Chester), run by access centre staff but on a part-time basis does not appear to have fully satisfied demand for a service in the area. The access centre appears to be only a part solution to problems of access in South Cheshire, and a significant number of people are still experiencing great difficulty or finding it impossible to find an NHS dentist in this area

In a study based in Buckinghamshire, where in 1994 16\% of people reported being unable to access regular dental care, 27\% said that they received private care with one third of these reporting that this was because they had been unable to find an NHS dentist. ${ }^{9}$ The reports from people experiencing difficulties in obtaining NHS dental care in Cheshire also indicates that the uptake of private dental care is sometimes as a direct result of the lack of availability of an NHS alternative. Some have also expressed concern that the lack of availability of NHS dental services may have stopped some attending for regular dental 'checkups' and even delayed necessary dental treatment. ${ }^{8}$ The South Cheshire study does suggest that this is the case. Although some dental practices are listed as still taking NHS patients, in reality a long waiting list can exist and those wanting dental care are left hanging on for several months by a promise of being seen at some point in the future. Further research is needed to investigate the extent of the waiting list for NHS care since this may be masking how many people are failing to obtain regular NHS dental care, and whether the oral health of the population has begun to suffer as a result.

The author wishes to thank Amanda Evans, Public Health Analyst, Central Cheshire Primary Care Trust and Carole Walker, Research Assistant for their help in gathering and presenting the data. Funding for the study was received from South Cheshire Health Authority.

1. British Dental Association. New BDA survey shows access to NHS dentistry getting worse. BDA Press release PR40.99, April 1999.

2. Sarll D W. Measuring politicians; concerns about oral health care in the British National Health Service. Community Dent Health 2001; 1: 249-255.

3. Modernising NHS Dentistry - Implementing the NHS Plan. London: Department of Health, September 2000

4. Lord Hunt of Kings Heath. House of Lords Hansard. 14th May 2002: Column 133

5. Buck D, Newton JT. The privatisation of NHS dentistry? A national snapshot of general dental practitioners. BrDent J 2001; 190: 115-118.

6. Anderson R. NHS Direct and access to dental care. Br Dent J 1999; 187: 634-636.

7. Department of Health, Press Release 1999/0566: 30 'phone and go'centres announced to improve patient access to dentists, 28th September 1999.

8. British Dental Association Press and Parliamentary Department. Problems of access to NHS dentistry; Harris poll (August 1998). BDA Media and Parliamentary briefing, April 2000.

9. Falcon H C, Hurst C P. A public perception of access to NHS dentistry. Br Dent J 1998; 184: $351-353$ 